and 2 out of 103 unsuspected instances in the younger group, and 2 out of 9 suspected and 11 out of 29 unsuspected in the older group. The division between suspected and unsuspected cases was dependent on the quality of the referral, which was often limited.

Our findings suggest that the EEG gives useful diagnostic information in a little over a third of cases. However, in practice the effect is likely to be reduced by such factors as the primacy of a clear clinical diagnosis in suspected epilepsy, the nature of the EEG report being usually suggestive rather than indicative, and the superiority of other investigations (e.g. neuroimaging) in certain situations. The EEG test remains important in the differential diagnosis of both possible cerebral dysfunction (encephalopathy) and seizures, as well as the monitoring of epilepsy. In order to keep the rate of uninformative tests to a minimum, clinicians should carefully describe the presenting signs and symptoms, considering whether these are consistent with epilepsy and whether other investigations are preferable. This information should be included in the EEG referral to improve the utility of the subsequent report.

FENTON, G.W. \& STANDAGE, K. (1993) Clinical electroencepahalography in a psychiatric service. Canadian Journal of Psychiatry, 38, 333-338.

STONE, S. \& MORAN, G. (2003) The utility of EEG in psychiatry and aggression. Psychiatric Bulletin, 27, 171-172.

Shweta Gangavati Senior House Officer Leicestershire Partnership NHS Trust,

*Chris Meakin Consultant Psychiatrist, Bradgate Mental Health Unit, Groby Road, Leicester LE3 9EJ, email: christopher.meakin@leicspart.nhs.uk

doi: 10.1192/pb.32.4.152b

\section{The Bournewood gap is not as wide as it sometimes seems}

In response to Singhal et al (Psychiatric Bulletin, January 2008, 32, 17-20), I would like to point out a common misunderstanding with regards to the European Court of Justice judgement on the Bournewood case [H.L. v. UK, 2005]. The authors give a good description of the case itself, but they then confuse its specifics with the details of the so-called 'Bournewood gap'. This, however, fails to take account of the actual judgement, which concludes that the reason why the court ruled against the Bournewood Trust in that particular case was because of the specific circumstances that amounted to a deprivation of liberty under Article 5 of the Human Rights Act 1998. They listed a number of points regarding complete control over the patient's movements and choices including not allowing visitors and home visits to his carers. It was the completeness of control exercised by the treating team that was the issue at hand rather than the more general point of $\mathrm{H}$.L. lacking capacity to consent to his stay in hospital. The court specifically pointed out that this case should not be considered as a precedent but should be considered on its merits alone. While appreciating that one English judge in particular has given the meaning of de facto detention a broader interpretation in his particular judgement, the original European Court of Justice ruling should not be ignored.

When the Ministry of Justice introduced the deprivation of liberty safeguards in the Mental Health Act 2007 (thus amending the Mental Capacity Act 2005) they failed to give any reasonable explanation why the safeguards were necessary. Their official argument that the amendment will bridge the so-called Bournewood gap has to be viewed with some scepticism. This is because the definition of people who fall within the deprivation of liberty safeguards goes much beyond the original case brought to the European Court of Justice. An easier interpretation would have been to use the Mental Capacity Act 2005 to make decisions in the best interests of a patient and thus bridge the Bournewood gap. There was no specific need for additional legislation in this area but it falls in line with a number of local and national decisions taken with anticipatory obedience in order not to fall foul of some perceived legal obligation.

This anticipatory obedience or defensiveness has certainly contributed to giving the Human Rights Act a bad name and the same is potentially possible with the Mental Capacity Act if people get the impression that they have to do unreasonable and additional paperwork in order to comply with the Act. Acting in anticipatory obedience therefore has negative consequences for the perception of perfectly reasonable legislation on top of creating a lot of additional administrative work and costs for the respective authorities who are charged with the execution of the new amendments. As clinicians we ought to contribute to a sensitive interpretation of the new legislation and prevent a situation where staff on the ground consider far too many people to be in danger of potential Human Rights Act breaches.

\section{H. L. v. UK [2005] ECHR}

Peter Lepping Consultant Psychiatrist/Honorary Senior Lecturer, University ofWales, CentralWrexham Community Mental Health Team, North EastWales NHS Trust, 16 Grosvenor Road, Wrexham LL11 1BU, Wales, email: peter.lepping@new-tr.wales.nhs.uk

doi: 10.1192/pb.32.4.153

\section{Blood-borne virus testing and Hepatitis B immunisation in specialist alcohol and drugs service}

In the UK, which has among the highest rates of recorded illegal substance misuse in the Western world, 34\% of people diagnosed with Hepatitis B, over $90 \%$ diagnosed with Hepatitis C and 5.6\% diagnosed with HIV were associated with injecting drug use.

In our cross-sectional survey on 150 individuals under active management by the Trust Alcohol and Drug Services based at Great Yarmouth, 3\% were diagnosed positive for Hepatitis B, 19\% for Hepatitis $\mathrm{C}$ and $2 \%$ for HIV. About half had no documentation regarding blood-borne viruses; 36 had at least one dose of Hepatitis B vaccine, but only 18 had three doses. Those who showed a trend towards completing Hepatitis B immunisation were in the age group above 30 years old, known to the services for more than 2 years, injectors, those who accepted the offer of immunisation and those positive for Hepatitis C. This is of concern as studies show an emergence of increasing incidence of blood-borne viruses among new, young and vulnerable drug users.

At the time of our study, $22 \%$ individuals shared injecting equipment. Injecting is not only a key factor in the transmission of blood-borne viruses, but also plays a significant role in deaths from overdose, accounting for more than 7\% of all the deaths among those aged 1539 years old in 2004 (European Monitoring Centre for Drugs and Drug Addiction, 2006).

We recommend the following: (1) clinicians need to collect, keep, analyse and make effective use of patient data including sexual health and injecting practice; (2) drug and alcohol services should increase awareness of harm from injecting drug use, with particular regard to bloodborne viruses and overdose; and (3) effective treatment goals should include testing, immunisation and treating of blood-borne viruses for all service users.

EUROPEAN MONITORING CENTRE FOR DRUGS AND DRUG ADDICTION (2006) Drug-Related Infectious Diseases and Drug-Related Deaths. Annual Report. The State of the Drug Problem in Europe. European Monitoring Centre for Drugs and Drug Addiction (http://www.emcdda.europa.eu/html.cfm/ index41529EN.html).

*Vellingiri Raja Badrakalimuthu Speciality Registrar, Northumberland, Tyne and Wear NHS Trust, Northgate Hospital, Great Yarmouth NR30 1BU, email: dr_vellingiriraja@yahoo.co.uk, Daphne Rumball Consultant Psychiatrist, Drug and Alcohol Services, Norfolk and Waveney Mental Health Partnership NHS Trust

doi: $10.1192 / \mathrm{pb} .32 .4 .153 a$ 